\title{
Cloud droplet activation and surface tension of mixtures of slightly soluble organics and inorganic salt
}

\author{
S. Henning ${ }^{1}$, T. Rosenørn ${ }^{1}$, B. D’Anna ${ }^{2}$, A. A. Gola ${ }^{3}$, B. Svenningsson ${ }^{1}$, and M. Bilde ${ }^{1}$ \\ ${ }^{1}$ Department of Chemistry, University of Copenhagen, Universitetsparken 5, DK-2100 Copenhagen Ø, Denmark \\ ${ }^{2}$ Department of Chemistry, University of Oslo, N-0315 Oslo, Norway \\ ${ }^{3}$ Department of Physical Chemistry, Medical University of Wroclaw, pl. Nankiera 1, 50-140 Wroclaw, Poland
}

Received: 29 October 2004 - Published in Atmos. Chem. Phys. Discuss.: 10 November 2004

Revised: 27 January 2005 - Accepted: 12 February 2005 - Published: 24 February 2005

\begin{abstract}
Critical supersaturations for internally mixed particles of adipic acid, succinic acid and sodium chloride were determined experimentally for dry particles sizes in the range $40-130 \mathrm{~nm}$. Surface tensions of aqueous solutions of the dicarboxylic acids and sodium chloride corresponding to concentrations at activation were measured and parameterized as a function of carbon content. The activation of solid particles as well as solution droplets were studied and particle phase was found to be important for the critical supersaturation. Experimental data were modelled using Köhler theory modified to account for limited solubility and surface tension lowering.
\end{abstract}

\section{Introduction}

Atmospheric aerosols affect global climate directly via interaction with electromagnetic radiation (e.g. Andronova et al., 1999; Jacobson, 2001; Houghton et al., 2001) and indirectly via their role in cloud formation and importance for cloud droplet number and cloud optical properties (Albrecht, 1989; Hansen et al., 1997; Rosenfeld and Woodley, 2000; Lohmann, 2002; Liepert et al., 2004).

The ability of an aerosol particle to become a cloud droplet depends on the chemical composition and physical properties of the particle and only a fraction of all particles are able to grow into cloud droplets under atmospheric conditions. Aerosol particles that can grow into cloud droplets (activate) under atmospheric supersaturations are cloud condensation nuclei $(\mathrm{CCN})$. The supersaturation needed to activate the particles is called critical supersaturation.

In the atmosphere particles may be solid or liquid, they may exist as solution droplets or even as multiphase systems (e.g. Prenni et al., 2001; Brooks et al., 2003; Marcolli et al.,

Correspondence to: M. Bilde

(mbilde@kiku.dk)
2004). Furthermore, particles may go from one phase to the other during cloud processing. Recently it has been suggested and experimentally verified that particle phase plays a major role for the activation of particles consisting of slightly soluble organic compounds (Bilde and Svenningsson, 2004; Hori et al., 2003; Broekhuizen et al., 2004). In the atmosphere particles are most likely to be mixtures of organic and inorganic components. Even if a purely organic particle exists it is likely to collect inorganic material during cloud processing. While some data on the cloud droplet activation of pure (e.g. Cruz and Pandis, 1997; Corrigan and Novakov, 1999; Prenni et al., 2001; Raymond and Pandis, 2002; Kumar et al., 2003) and multi-component solid particles have recently appeared (e.g. Cruz and Pandis, 1998; Hegg et al., 2001; Raymond and Pandis, 2003; Kumar et al., 2003) few such data on multi-component solution droplets have been reported (Broekhuizen et al., 2004).

In this work the importance of particle phase for cloud droplet activation of multi-component particles containing inorganic as well as organic compounds is therefore addressed. As representative of inorganic aerosol components the ubiquitous salt sodium chloride was chosen. As organic components adipic and succinic acid, which have been identified as common compounds in the water-soluble fraction of organic aerosols (Saxena and Hildemann, 1996), were chosen. These acids are known to be moderately surface active and as discussed in recent papers (Facchini et al., 1999; Shulman et al., 1996) this can affect the critical supersaturation of atmospheric aerosol particles, but experimental data and parameterizations of relevant drop surface tensions are rare. Therefore surface tension measurements of the mixtures at relevant concentrations were conducted, parameterized as a function of the carbon content of the individual acids and incorporated in a Köhler model taking into account limited solubility. It has recently been suggested (Li et al., 1998; Sorjamaa et al., 2004) that partitioning of surface active organic compounds between bulk and surface in activating droplets

(C) 2005 Author(s). This work is licensed under a Creative Commons License. 


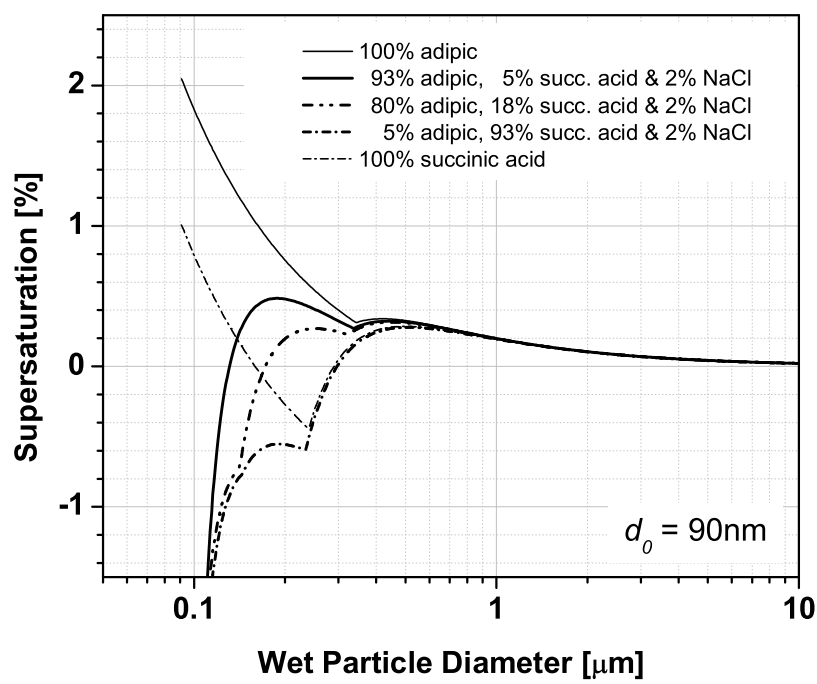

Fig. 1. Köhler curves accounting for limited solubility for initially dry particles with a diameter of $90 \mathrm{~nm}$ of ternary mixtures of adipic and succinic acid and sodium chloride. For comparison the curves for pure adipic and succinic acid are also given.

affects the critical supersaturation. This was shown experimentally and theoretically for sodium dodecyl sulfate (SDS) particles and theoretically for particles consisting of ammonium sulfate and cis-pinonic acid. Since the surface activity of the compounds studied herein is small the effect of partitioning is not taken into account in this work.

\section{Theory}

Two competing effects determine the vapor pressure of water over an aqueous solution droplet: the solution effect (Raoult's law) which tends to decrease vapor pressure and the curvature (Kelvin) effect which tends to increase the vapor pressure. The vapor pressure of water over an aqueous solution droplet relative to that over a flat surface is given by the Köhler equation (Köhler, 1936):

$S=\frac{p}{p_{0}}=a_{\mathrm{w}} \cdot \exp \left(\frac{4 M_{\mathrm{w}} \sigma}{R T \rho D_{\mathrm{pw}}}\right)$

$a_{\mathrm{w}}$ is the water activity, $D_{\mathrm{pw}}$ is droplet diameter, $M_{\mathrm{w}}$ is the molar weight of water, $\sigma$ is the air-liquid surface tension, $R$ is the gas constant, $T$ is temperature and $\rho$ is the density of the solution. The Raoult term in classical Köhler theory applies only for completely soluble substances whereas recent modifications take limited solubility into account as follows (Shulman et al., 1996; Kulmala et al., 1997; Laaksonen et al., 1998). For a droplet containing several species the water activity can be approximated by:

$a_{\mathrm{w}}=\frac{n_{\mathrm{w}}}{n_{\mathrm{w}}+\sum_{i} v_{i} n_{i}}$ $n_{i}$ is the number of moles of compound $i, v_{i}$ is the van't Hoff factor and $n_{\mathrm{w}}$ number of moles water (Pruppacher and Klett, 1997).

By assuming that compound $i$ is homogeneously distributed in the aqueous phase and that its concentration is determined by its water solubility only, the number of moles of compound $i$ in a multicomponent solution droplet can be expressed as:

$n_{\mathrm{i}}=\operatorname{Min}\left\{\frac{\left(D_{\mathrm{pw}}^{3}-d_{0}^{3}\right) \cdot C_{\mathrm{sat}}}{M_{i}}, \frac{\beta_{i} \cdot \rho_{0} \cdot d_{0}^{3}}{M_{i}}\right\} \cdot \frac{\pi}{6}$

where $\beta_{\mathrm{i}}$ is the mass fraction of compound $i$ in the initial dry particle of diameter $d_{0}$ and $C_{\mathrm{sat}}$ is the water solubility of compound $i$ (mass per volume). Assuming additivity of volumes the density of the dry particle $\rho_{0}$ is given as:

$\frac{1}{\rho_{0}}=\sum_{i} \frac{\beta_{i}}{\rho_{i}}$

Water solubilities of $25 \mathrm{gl}^{-1}$ and $88 \mathrm{gl}^{-1}$ were used for adipic and succinic acid, respectively (Saxena and Hildemann, 1996). A van't Hoff factor of 1 and 2 was used for organic acid (Kiss and Hansson, 2004) and $\mathrm{NaCl}$, respectively.

As predicted by Shulman et al. (1996), the Köhler curve obtained using modified Köhler theory has up to three maxima (Fig. 1). The cusps represent the points where adipic and succinic acid respectively are completely dissolved. The maximum at the highest wet diameter represents a solution droplet were all components are dissolved. Therefore the corresponding supersaturation is identical with that obtained by assuming that the organic acids are infinitely soluble in water (classical Köhler theory). The supersaturations corresponding to the first two maxima may in some cases be higher than the critical supersaturation obtained from traditional Köhler theory and as explained in Bilde and Svenningsson (2004) they can be viewed as an activation barrier which is due to the presence of a undissolved solid core of organic acid(s). This barrier is eliminated when the activating particle starts out as a solution droplet. The magnitude of the first two maxima may be dramatically influenced by the presence of small amounts of soluble material whereas the third maxima is less influenced.

\section{Experimental}

Aqueous solutions of two dicarboxylic acids (adipic acid, Riedel-de Haën, purity $\geqslant 99.8 \%$; succinic acid, Merck, purity $>99.5 \%$ ) and sodium chloride (Riedel-de Haën, purity $>99.8 \%$ ) in three different proportions (mix. 1: $93 \%$ adipic acid (aa), $5 \%$ succinic acid (sa), $2 \%$ sodium chloride $(\mathrm{NaCl})$; mix. 2: $80 \%$ aa, $18 \%$ sa, $2 \% \mathrm{NaCl}$; mix. $3: 5 \%$ aa, $93 \%$ sa, $2 \% \mathrm{NaCl}$ ) were prepared. To avoid impurities all glassware was cleaned with purified water (MilliQ) and all solutions 
(a)

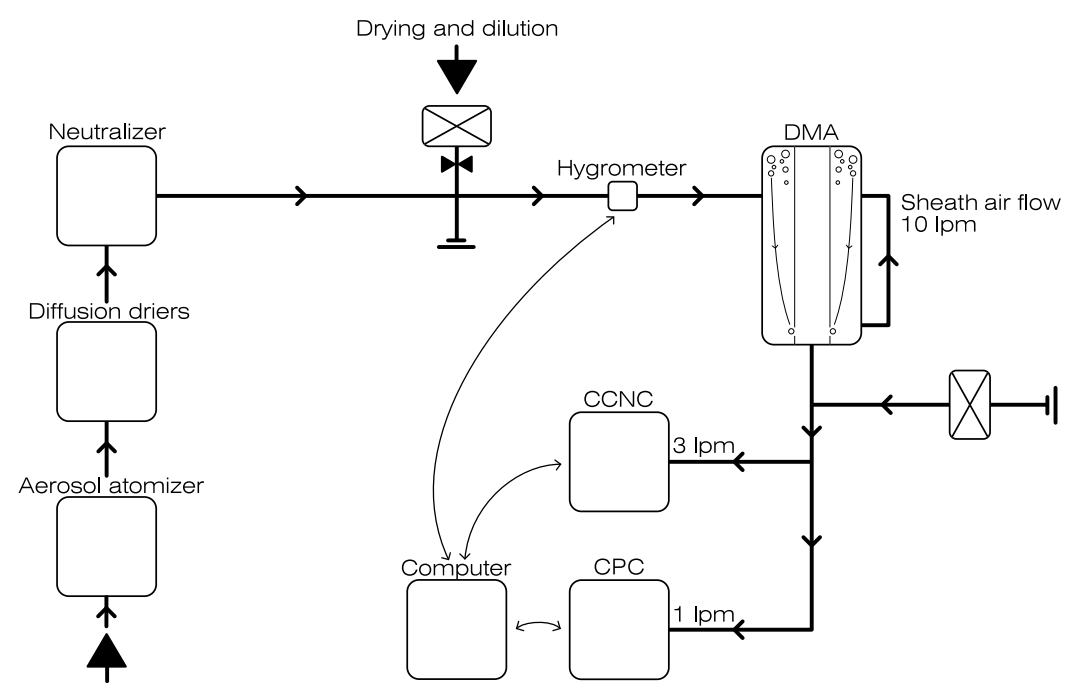

(b)

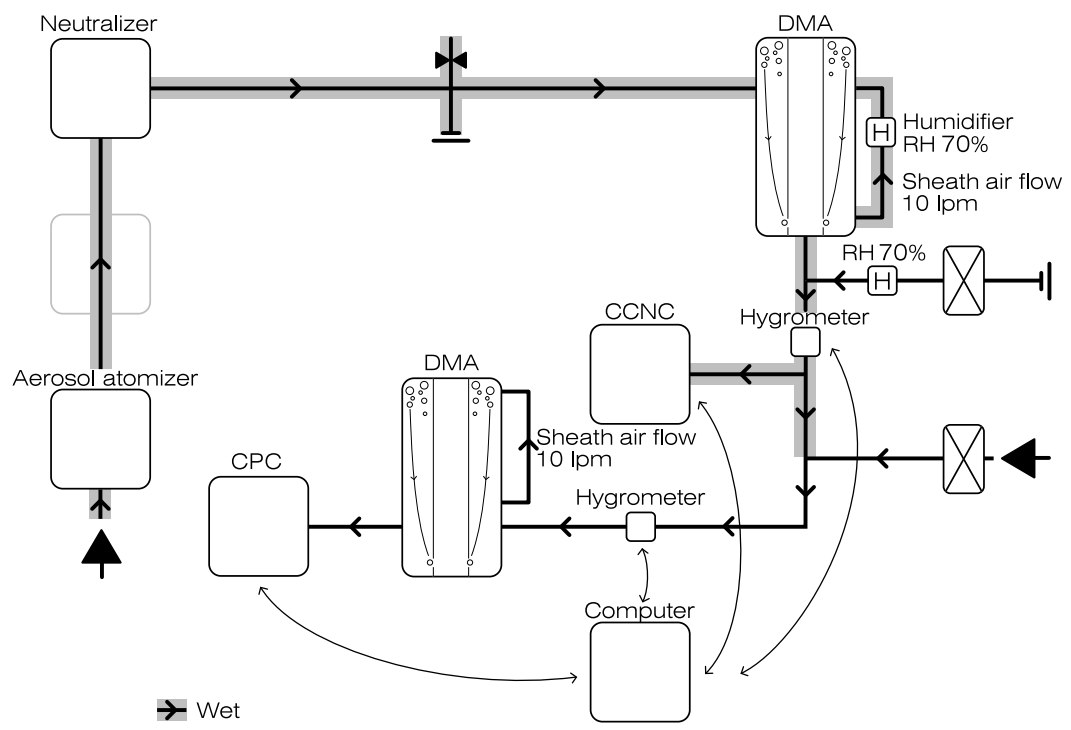

Fig. 2. Experimental setup of CCNC measurements for (a) initially dry particles and (b) solution droplets. In (b) the grey highlighted lines show the pathway of the wet kept particles.

were prepared with commercial available ultra pure water (Fluka, 7732-18-5).

\subsection{Surface tension measurements}

Surface tensions of the water-organic-inorganic salt systems were performed with the De Nöuy method (De Nöuy, 1919; Freud and Freud, 1930) over the temperature range 273$306 \mathrm{~K}$.
The apparatus consists of a De Nöuy tensiometer (Krüss GmbH, Hamburg, Instrum. Nr. K6, type 90331), a PlatinumIridium ring of radius $r$, and a glass vessel for the solutions. For measurement a Pt-ring is pulled through the liquid/air interface and the maximum downward force directed to the ring is measured. The surface tension is determined by

$\sigma=\frac{P}{4 \pi r} F$

where $P$ is the detachment force and $F$ is a dimensionless 


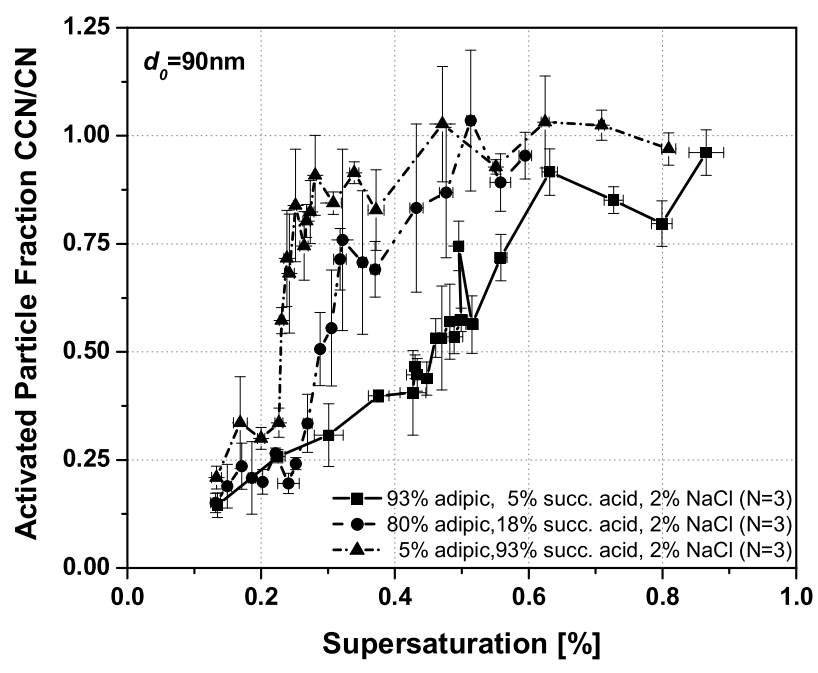

Fig. 3. Example of activation measurements for ternary mixtures of adipic and succinic acid at a dry particle diameter $d_{0}=90 \mathrm{~nm}$. $\mathrm{N}$ is the number of scans included in the average and the bars give the standard deviation of the measurements.

correction factor determined experimentally (Harkins and Jordan, 1930). The temperature was controlled to within $\pm 0.3 \mathrm{~K}$ either by a regulated stream of cold nitrogen through a double-walled beaker containing the mixtures or by a warm water bath.

The instrument was tested before every measurement series using ion-exchanged, doubly distillated water as standard. The result found for water $\left(72.49 \mathrm{mNm}^{-1} \pm 0.82 \mathrm{mNm}^{-1}\right.$ at $\left.295 \mathrm{~K}\right)$ agrees well with the literature value $\left(72.75 \mathrm{mNm}^{-1}\right.$ at $293 \mathrm{~K}$, Vargaftik et al., 1983) and the temperature dependent parametrization given by Pruppacher and Klett (1997) $\left(72.50 \mathrm{mNm}^{-1}\right.$ at $\left.295 \mathrm{~K}\right)$.

\section{$3.2 \mathrm{CCN}$-measurements}

Aerosol particles were generated by atomizing aqueous solutions in a constant output atomizer (TSI, 3076) and their ability to act as cloud droplets was studied in a static thermal gradient diffusion chamber (CCNC, University of Wyoming, CCNC-100B). The number of activated particles is detected via light scattering. A similar $\mathrm{CCNC}$ and the calibration of it has been described in Delene and Deshler (2000).

The instruments supersaturation was calibrated using dry monodisperse $\mathrm{NaCl}$ and $\left(\mathrm{NH}_{4}\right)_{2} \mathrm{SO}_{4}$ particles over the supersaturation range of $0.2-2 \%$. Theoretical values were calculated via Köhler Theory as described above. The resulting calibration equation $\left(R^{2}=0.9959\right)$ was applied to all experimental data.

Two types of experiments were performed: 1) dry measurements where the aerosol particles were dried before entering the cloud chamber and 2) wet measurements, where the particles entered the cloud chamber as solution droplets supersaturated in respect to the organics but subsaturated in respect to sodium chloride.

For the dry measurements (Fig. 2a) the generated aerosol was dried to relative humidities in the range $1-20 \%$ using diffusion dryers and a specific diameter was selected using a differential mobility analyzer (DMA, TSI, 3080). Particles generated in this way are referred to as initially dry particles. Downstream of the DMA the CCNC was used to determine the particles critical supersaturation. Particle number was measured as a reference with a particle counter (TSI, CPC 3010).

Studies of evaporation rates of adipic and succinic acid (Bilde et al., 2003) show that evaporation over the time scale particles spend in the tubing in these experiments is negligible. This was confirmed by comparing the particle size selected by the first DMA to their size just before entering the CCNC.

In the set-up for the wet measurements (Fig. 2b) the diffusion dryers were bypassed and the particles entered the DMA wet. The sheath air of the DMA was humidified to $70 \%$. The monodisperse aerosol exiting the DMA was divided into two streams. One stream was kept at the humidity of $70 \%$ until entering the cloud chamber. The other stream was dried and the dry particle size was measured using a scanning mobility particle analyzer (TSI, SMPS 3934) consisting of a DMA and a CPC.

Throughout this work the supersaturation in the CCNC was varied between 0.2 and $2 \%$ for a fixed dry or dry adequate particle diameter in dry and wet experiments, respectively. The activated particle fraction, the number of $\mathrm{CCN}$ normalized to the total particle number $(\mathrm{CN})$, is ideally a step function. In reality the step is not always very steep (Fig. 3). By choosing a particle diameter via DMA technique a quasi monodisperse aerosol distribution is selected. The width of this distribution is dependent on the aerosol to sheath air flow ratio in the DMA and influences the slope in a plot of activated fraction versus supersaturation (e.g. Fig. 3). The critical supersaturation is the point of $50 \%$ activation and the DMA transfer function was taken into account when finding this point.

\section{Results and discussion}

Three different mixtures containing adipic acid, succinic acid and sodium chloride were investigated with respect to surface tension and activation behavior. The mass fraction of the inorganic salt was kept at $2 \%$ and the relative amounts of adipic and succinic acid were varied.

\subsection{Surface tension of mixtures}

To investigate surface tensions in the relevant concentration range, drop concentrations at activation were estimated using Köhler theory accounting for limited solubility. Surface 


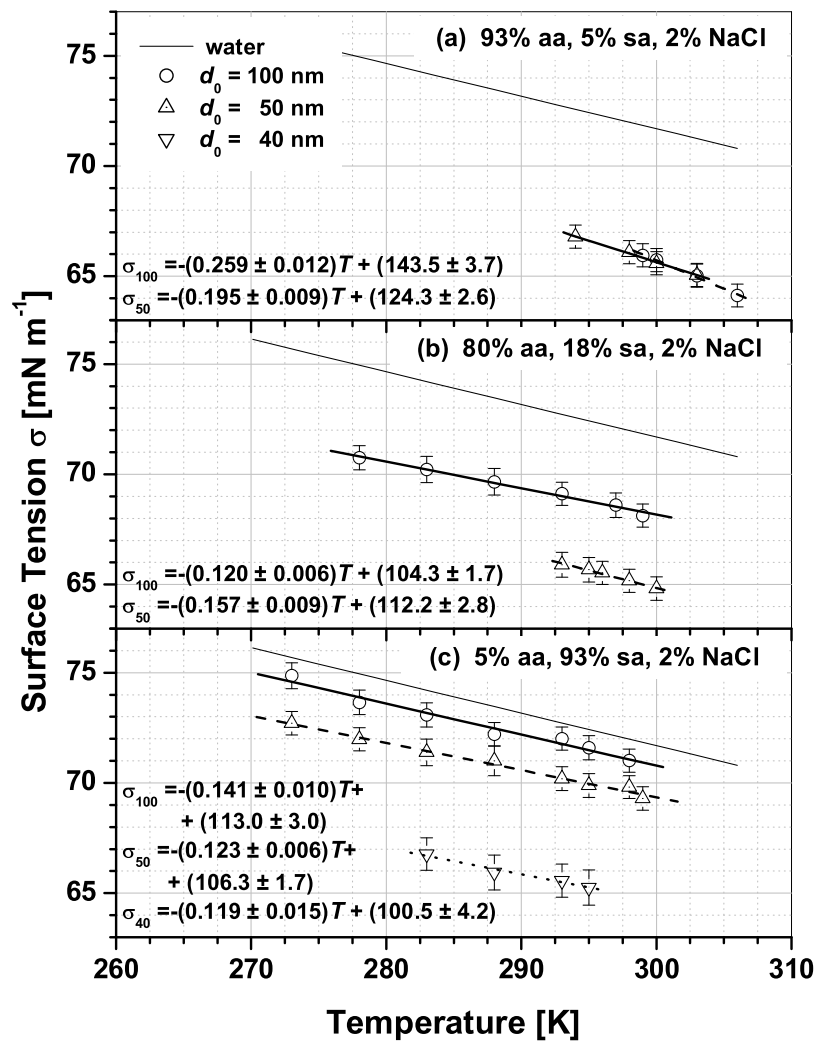

Fig. 4. Experimentally determined surface tensions of ternary mixtures of adipic and succinic acid including $\mathrm{NaCl}$ in water. Solution concentrations corresponding roughly to the concentration at activation for initially dry particles with diameters of 50 and $100 \mathrm{~nm}$ for pane (a) and (b) and 40, 50 and $100 \mathrm{~nm}$ for pane (c), respectively. Error bars represent a combined error of: relative error from the instrumentation $( \pm 0.3 \%)$, uncertainty in temperature controlling system $( \pm 0.3 \mathrm{~K}), \pm 0.3 \%$ of the mass fraction and standard deviation from fit $( \pm 0.3 \%)$.

tension measurements were performed using solutions corresponding roughly to the concentrations at activation of initially dry particles with diameters of 50 and $100 \mathrm{~nm}$ for mix. 1 and 2 (Fig. $4 \mathrm{a}$ and b) and 40, 50 and $100 \mathrm{~nm}$ for mix. 3 (Fig. 4 c). The exact concentrations studied are given in Table 1 .

A linear temperature dependence was found for all three mass mixing ratios of adipic acid, succinic acid and $\mathrm{NaCl}$ with water (Fig. 4). Slopes, offsets and errors of the linear least square fits are given in Fig. 4.

In Fig. 4a the solute concentration is very close to the solubility limit of adipic acid for the studied solutions and the surface tension is therefore similar for both solutions. Pure adipic acid is found to be more surface active than pure succinic acid (Shulman et al., 1996; Dash and Mohanty, 1997). In consistence with that a stronger surface tension lowering is observed with increasing adipic acid concentration of the solution.
Table 1. Mass of adipic acid (aa), succinic acid (sa), sodium chloride $(\mathrm{NaCl})$ and water in each individual solution used for surface tension measurements. Concentrations correspond roughly to the point of activation of initially dry particles at different dry diameters $d_{0}$.

\begin{tabular}{|c|c|c|c|c|}
\hline$d_{0}$ & $m_{\mathrm{aa}}$ & $m_{\mathrm{sa}}$ & $m_{\mathrm{NaCl}}$ & $m_{\text {water }}$ \\
\hline $\mathrm{nm}$ & $\mathrm{g}$ & g & $\mathrm{g}$ & $\mathrm{g}$ \\
\hline & \multicolumn{4}{|c|}{$93 \%$ aa, $5 \%$ sa, $2 \% \mathrm{NaCl}$} \\
\hline 100 & 2.257 & 0.674 & 0.271 & 96.954 \\
\hline \multirow[t]{2}{*}{50} & 2.016 & 1.337 & 0.535 & 96.129 \\
\hline & \multicolumn{4}{|c|}{$80 \%$ aa, $18 \%$ sa, $2 \% \mathrm{NaC}$} \\
\hline 100 & 0.770 & 0.175 & 0.019 & 99.038 \\
\hline \multirow[t]{2}{*}{50} & 2.192 & 2.393 & 0.264 & 95.305 \\
\hline & \multicolumn{4}{|c|}{$5 \%$ aa, $93 \%$ sa, $2 \% \mathrm{NaCl}$} \\
\hline 100 & 0.036 & 0.674 & 0.015 & 99.294 \\
\hline 50 & 0.106 & 1.860 & 0.040 & 98.005 \\
\hline 40 & 1.742 & 6.135 & 0.947 & 91.219 \\
\hline
\end{tabular}

According to Facchini et al. (1999) surface tension lowering of atmospheric water samples can be described by the Szyszkowski-Langmuir equation:

$\sigma=\sigma_{\mathrm{w}}(T)-a T \ln (1+b C)$

where $C$ is the concentration of soluble carbon given in moles of carbon per kg of water. Applying Eq. (6) to multiple mixtures, it is required that the coefficients $a$ and $b$ are determined from experimental data for all mixing ratios investigated. A modification of this equation has been tested and proven successful for all mixtures studied herein.

$\sigma=\sigma_{\mathrm{w}}(T)-\sum_{i} \chi_{i} a_{i} T \ln \left(1+b_{i} C\right)$

Equation (7) allows calculation of the surface tension of mixtures at the temperature $T$ on the basis of the coefficients $a_{i}$, $b_{i}$ for the pure compounds fulfilling Eq. (6) and $\chi_{i}$, the carbon content of compound $i$ ( $C_{i}$ in moles of carbon per $\mathrm{kg}$ of water) in respect to the total soluble carbon $C$ in solution:

$\chi_{i}=\frac{C_{i}}{C}$

Recently Kiss et al. (2004) have shown that high concentrations of inorganic salts can enhance surface tension lowering of humic-like substances (HULIS). Due to low inorganic salt concentrations of the here investigated mixtures this effect was assumed to be negligible.

Values for $a_{i}$ and $b_{i}$ of pure adipic acid were derived by fitting Eq. (6) to data points given by Shulman et al. (1996) 
Table 2. Coefficients $a_{i}$ and $b_{i}$ of pure adipic acid and succinic acid derived by fitting Eq. (6) to $N$ data points.

\begin{tabular}{lccc}
\hline compound & $N$ & $a_{i}$ & $b_{i}$ \\
\hline succinic acid & 6 & 0.0264 & 0.286 \\
adipic acid & 4 & 0.0106 & 11.836 \\
\hline
\end{tabular}

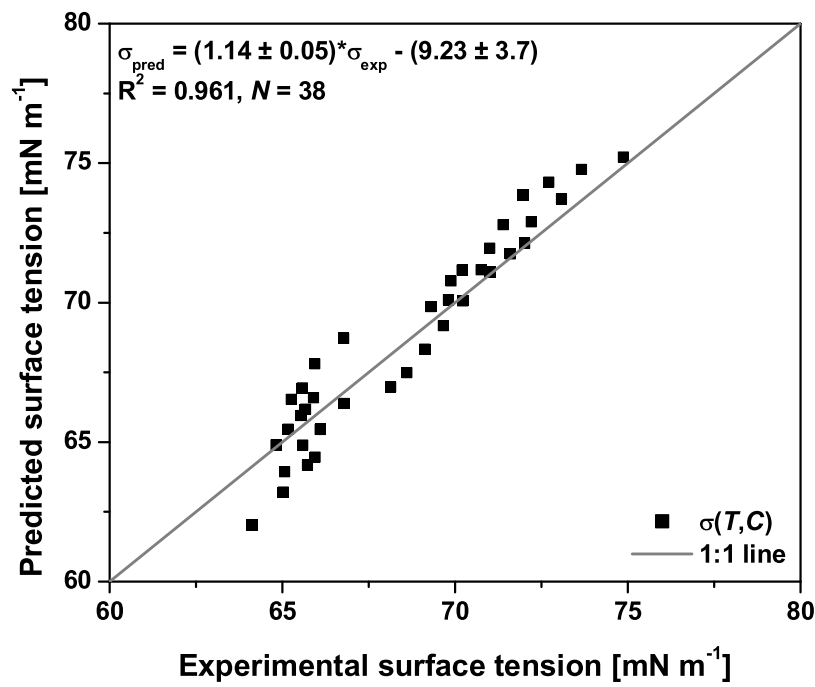

Fig. 5. Predicted surface tensions of mixtures containing dicarboxylic acids and sodium chloride using Eq. (7) versus experimental derived surface tensions in a temperature range of $273 \mathrm{~K} \leq T \leq 306 \mathrm{~K}$ and a total soluble carbon concentration in water of $0.25 \mathrm{~mol} \mathrm{~kg}^{-1} \leq[C] \leq 3.06 \mathrm{~mol} \mathrm{~kg}^{-1}$.

(Table 2). Fitting coefficients for pure succinic acid are taken from Svenningsson et al. (2005) ${ }^{1}$.

Predicting surface tensions for the experimentally investigated solutions applying this approach leads to a good agreement (Fig. 5, $\mathrm{R}^{2}=0.956$ ) in the here considered temperature $(273 \mathrm{~K} \leq T \leq 306 \mathrm{~K})$ and concentration range $\left(0.25 \mathrm{~mol} \mathrm{~kg}^{-1} \leq[C] \leq 3.06 \mathrm{~mol} \mathrm{~kg}^{-1}\right)$. In general, mixtures close to the solubility limit were difficult to measure due to beginning precipitation. The precipitated compounds were resolvated by heating the solution, followed by cooling and immediate surface tension measurement. This procedure might explain the deviation from the 1:1 line in Fig. 5 for low surface tensions.

More work is needed to show if Eq. (7) is applicable for other organic compounds and for higher concentration of inorganic material.

\footnotetext{
${ }^{1}$ Svenningsson, B., Rissler, J., Swietlicki, E., Mircea, M., Bilde, M., Facchini, M. C., Decesari, S., Fuzzi, S., Zhou, J., Mønster, J., and Rosenørn, T.: Hygroscopic Growth and Critical Supersaturations for Mixed Aerosol Particles of Inorganic and Organic Compounds of Atmospheric Relevance, Atmos. Chem. Phys. Discuss., submitted, 2005.
}

\subsection{Cloud droplet activation}

Experimentally obtained critical supersaturations for initially dry particles (solid squares) and solution droplets (open circles) are given in Fig. 6. Theoretical critical supersaturations $\left(S_{\mathrm{c}, \text { theo }}\right)$ calculated using the surface tension of water $\left(\sigma_{\mathrm{w}}\right)$ are shown as grey lines and $S_{\mathrm{c} \text {, theo }}$ calculated using the surface tension at activation given in Eq. (7) $(\sigma)$ are shown as black lines. In both cases unbroken lines represent particles that were initially dry and dashed lines represent particles that were initially solution droplets.

It is clear from the measurements that there is a pronounced difference between the critical supersaturation of initially dry particles and solution droplets (containing the same amount of organic acids and $\mathrm{NaCl}$ ) when adipic acid is the dominating species. For a $90 \mathrm{~nm}$ particle containing $93 \%$ adipic acid the critical supersaturation is $0.32 \%$ for an initially dry particle. In comparison the critical supersaturation is $0.48 \%$ if the particle initially existed as an aqueous solution droplet.

This dependence of particle phase is related to the solubility of the organic compounds as explained previously and as can also be seen from Fig. 1. When the particle is initially dry it has a solid core at activation and the Köhler curve has two or three maxima. The first two maxima can be seen as a barrier to activation caused by the solid core. When the particle exists initially as a solution droplet there is no such barrier and activation follows the "traditional" Köhler curve corresponding to infinite solubility of the organic compounds. The difference in critical supersaturation between particles with different phases is dependent on the initial dry particle size and the effect is largest for the smallest particles. It can be seen from Fig. 6 that as adipic acid is replaced by succinic acid the importance of particle phase decreases because succinic acid is more soluble than adipic acid.

Solution droplets of the same size but different chemical compositions activate at quite similar supersaturations while critical supersaturations for initially dry particles (of the same initial size) can span a wide range. For solution droplets experimental values and theory taking the parameterized surface tension of the solution into account agree very well for all mixture types. In case of dry particles another effect seems to dominate the lowering of surface tension and the small particles activate at a higher critical supersaturation than predicted.

\section{Conclusions}

Surface tensions of mixtures of two slightly soluble organic acids and an inorganic salt were measured and parameterized as a function of carbon content of the individual acids and temperature. It was found that the actual surface tension of the droplet at activation is dependent on the mole fraction of both acids. 


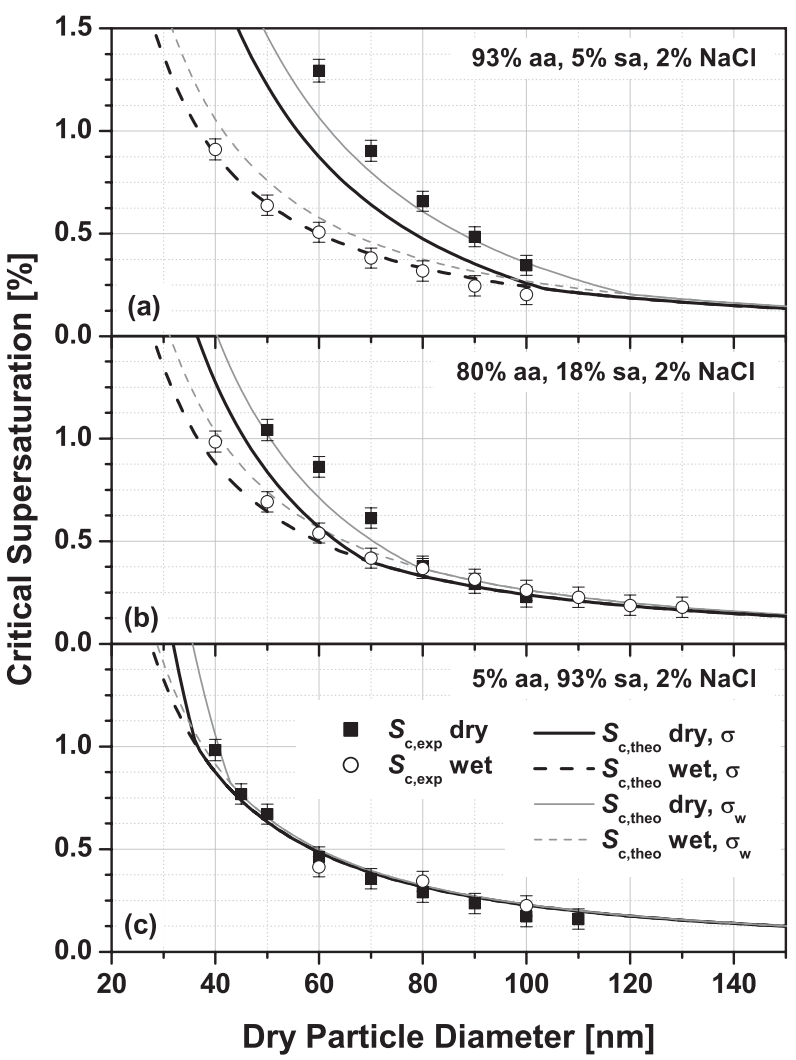

Fig. 6. Comparison of critical supersaturation as a function of particle size for initial dry (solid lines) and wet (dashed lines) particles of ternary mixtures of adipic acid, succinic acid and sodium chloride. Lines were obtained from modified Köhler theory at $T=298 \mathrm{~K}$, symbols are experimental results. The experimental uncertainty was calculated based on supersaturation calibration data. Please note the legend in pane (c).

Including surface tension lowering in Köhler theory taking limited solubility into account describes the activation behavior of the solution droplets well, but when a solid core is present theory underestimates critical supersaturation.

An important factor is the phase state of the particles. It was shown above that dry particles need much higher supersaturation to activate than their wet solution droplet counterpart. Knowledge of the phase state is therefore crucial otherwise an error in critical supersaturation of more than $50 \%$ can be made and thereby in predicting the $\mathrm{CCN}$ number.

Acknowledgements. This work is supported by the Swiss National Science Foundation, the Danish Natural Science Research Council and the Nordic Center of Excellence, Research Unit BACCI.

Edited by: U. Lohmann

\section{References}

Albrecht, B. A.: Aerosols, Cloud Microphysics, and Fractional Cloudiness, Science, 245, 1227-1230, 1989.

Andronova, N. G., Rozanov, E. V., Yang, F. L., Schlesinger, M. E., and Stenchikov, G. L.: Radiative forcing by volcanic aerosols from 1850 to 1994, J. Geophys. Res., 104, 16 807-16826, 1999.

Bilde, M. and Svenningsson, B.: CCN activation of slightly soluble organics: Importance of small amounts of inorganic salt and particle phase, Tellus, 56B, 128-134, 2004.

Bilde, M., Svenningsson, B., Mønster, J., and Rosenørn, T.: EvenOdd Alternation of Evaporation Rates and Vapor Pressures of C3-C9 Dicarboxylic Acid Aerosols, Environ. Sci. Technol., 37, 1371-1378, 2003.

Broekhuizen, K., Kumar, P. P., and Abbatt, J. P. D.: Partially soluble organics as cloud condensation nuclei: Role of trace soluble and surface active species, Geophys. Res. Lett., 31, L01 107 , doi:10.1029/2003GL018203, 2004

Brooks, S. D., Garland, R. M., Wise, M. E., Prenni, A. J., Cushing, M., Hewitt, E., and Tolbert, M. A.: Phase changes in internally mixed maleic acid/ammonium sulfate aerosols, J. Geophys. Res., 108, 4487, doi:10.1029/2002JD003204, 2003.

Corrigan, C. E. and Novakov, T.: Cloud condensation nucleus activity of organic compounds: a laboratory study, Atmos. Envir., 33, 2661-2668, 1999.

Cruz, C. N. and Pandis, S. N.: A study of the ability of pure secondary organic aerosol to act as cloud condensation nuclei, Atmos. Envir., 31, 2205-2214, 1997.

Cruz, C. N. and Pandis, S. N.: The effect of organic coatings on the cloud condensation nuclei activation of inorganic atmospheric aerosol, J. Geophys. Res., 103, 13 111-13 123, 1998.

Dash, U. N. and Mohanty, B. K.: Thermodynamic functions of solutions of homologous dicarboxylic acids in water plus acetone mixtures from surface tension measurements, Fluid Phase Equilibria, 134, 267-276, 1997.

De Nöuy, P. L.: A new apparatus for measuring surface tension, J. Gen. Physiology, 1, 521-524, 1919.

Delene, D. J. and Deshler, T.: Calibration of a photometric cloud condensation nucleus counter designed for deployment on a balloon package, J. Atmosp. Oc., 17, 459-467, 2000.

Facchini, M. C., Mircea, M., Fuzzi, S., and Charlson, R. J.: Cloud albedo enhancement by surface-active organic solutes in growing droplets, Nature, 401, 257-259, 1999.

Freud, B. B. and Freud, H. Z.: A theory of the ring method for the determination of surface tension, J. Am. Chem. Soc., 52, 17721782, 1930.

Hansen, J., Sato, M., and Ruedy, R.: Radiative Forcing and Climate Response, J. Geophys. Res., 102, 6831-6864, 1997.

Harkins, W. D. and Jordan, H. F.: A method for the determination of surface tension from the maximum pull on a ring, J. Am. Chem. Soc., 52, 1751-1772, 1930.

Hegg, D. A., Gao, S., Hoppel, W., Frick, G., Caffrey, P., Leaitch, W. R., Shantz, N., Ambrusko, J., and Albrechcinski, T.: Laboratory studies of the efficiency of selected organic aerosols as CCN, Atmos. Res., 58, 155-166, 2001.

Hori, M., Ohta, S., Murao, N., and Yamagata, S.: Activation capability of water soluble organic substances as CCN, J. Aerosol Sci., 34, 419-448, 2003.

Houghton, J. T., Ding, Y., Griggs, D. J., Noguer, M., van der Linden, P. J., Dai, X., Maskell, K., and Johnson, C.: Climate Change 
2001: The Scientific Basis. Contribution of Working Group I to the Third Assessment Report of the Intergovermental Panel on Climate Change, IPCC, 2001.

Jacobson, M. Z.: Strong radiative heating due to the mixing state of black carbon in atmospheric aerosols, Nature, 409, 695-697, 2001.

Kiss, G. and Hansson, H. C.: Application of osmolality for the determination of water activity and the modelling of cloud formation, Atmos. Chem. Phys. Discuss., 4, 7667-7689, 2004,

\section{SRef-ID: 1680-7375/acpd/2004-4-7667.}

Kiss, G., Tombácz, E., and Hansson, H. C.: Surface tension effects of humic-like substances in the aqueous extract of tropospheric fine aerosol, J. Atmos. Chem., accepted, 2004.

Köhler, H.: The nucleus in and the growth of hygropscopic droplets, Trans. Faraday Soc., 32, 1936.

Kulmala, M., Laaksonen, A., Charlson, R. J., and Korhonen, P.: Clouds without supersaturation, Nature, 388, 336-337, 1997.

Kumar, P. P., Broekhuizen, K., and Abbatt, J. P. D.: Organic acids as cloud condensation nuclei: Laboratory studies of highly soluble and insoluble species, Atmos. Chem. Phys., 3, 509-520, 2003,

\section{SRef-ID: 1680-7324/acp/2003-3-509.}

Laaksonen, A., Korhonen, P., Kulmala, M., and Charlson, R. J.: Modification of the Köhler equation to include soluble trace gases and slightly soluble substances, J. Atmos. Sci., 55, 853862, 1998.

Li, Z. D., Williams, A. L., and Rood, M. J.: Influence of soluble surfactant properties on the activation of aerosol particles containing inorganic solute, J. Atmos. Sci., 55, 1859-1866, 1998.

Liepert, B. G., Feichter, J., Lohmann, U., and Roeckner, E.: Can Aerosols Spin Down the Water Cycle in a Warmer and Moister World?, Geophys. Res. Lett., 31, L06207, doi:10.1029/2003GL019060, 2004.

Lohmann, U.: A Glaciation Indirect Aerosol Effect Caused by Soot Aerosols, Geophys. Res. Lett., 29, 1052, doi:10.1029/2001GL014357, 2002.
Marcolli, C., Luo, B. P., and Peter, T.: Mixing of the organic aerosol fractions: Liquids as the thermodynamically stable phases, J. Phys. Chem., 108, 2216-2224, 2004.

Prenni, A. J., DeMott, P. J., Kreidenweis, S. M., Sherman, D. E., Russell, L. M., and Ming, Y.: The effects of low molecular weight dicarboxylic acids on cloud formation, J. Phys. Chem., 105, 11 240-11 248, 2001.

Pruppacher, H. R. and Klett, J. D.: Microphysics of clouds and precipitation, Kluwer Academic Publishers, Dordrecht, 2 edn., 1997.

Raymond, T. M. and Pandis, S. N.: Cloud activation of singlecomponent organic aerosol particles, J. Geophys. Res., 107, 4787, doi:10.1029/2002JD002159, 2002.

Raymond, T. M. and Pandis, S. N.: Formation of cloud droplets by multicomponent organic particles, J. Geophys. Res., 108, 4469, doi:10.1029/2003JD003503, 2003.

Rosenfeld, D. and Woodley, W. L.: Deep Convective Clouds With Sustained Supercooled Liquid Water Down to -37.5 Degrees C, Nature, 405, 440-442, 2000.

Saxena, P. and Hildemann, L. M.: Water-Soluble Organics in Atmospheric Particles: a Critical Review of the Literature and Application of Thermodynamics to Identify Candidate Compounds, J. Atmos. Chem., 24, 57-109, 1996.

Shulman, M. L., Jacobson, M. C., Charlson, R. J., Synovec, R. E., and Young, T. E.: Dissolution Behavior and Surface Tension Effects of Organic Compounds in Nucleating Cloud Droplets, Geophys. Res. Lett., 23, 277-280, 1996.

Sorjamaa, R., Raatikainen, T., and Laaksonen, A.: The role of surfactants in Köhler theory reconsidered, Atmos. Chem. Phys., 4, 2107-2117, 2004,

SRef-ID: 1680-7324/acp/2004-4-2107.

Vargaftik, N. B., Volkov, B. N., and Voljak, L. D.: International Tables of the Surface-Tension of Water, J. Phys. Chem. Ref. Data, 12, 817-820, 1983. 